\title{
Economic, Health and Physical Impacts of COVID-19 Pandemic in Sub-Saharan African Regions: A Cross Sectional Survey
}

Khathutshelo Percy Mashige, (iD) 'Uchechukwu Levi Osuagwu, (D) ${ }^{1,2}$ Sekar Ulagnathan, ${ }^{3}$ Bernadine N Ekpenyong, ${ }^{1,4}$ Emmanuel Kwasi Abu, (iD) ${ }^{5}$ Piwuna Christopher Goson, ${ }^{6}$ Raymond Langsi, ${ }^{7}$ Obinna Nwaeze, ${ }^{8}$ Chikasirimobi G Timothy, (iD) ${ }^{9}$ Deborah Donald Charwe, ${ }^{10}$ Richard Oloruntoba, (D) 11 Chundung Asabe Miner, ${ }^{12}$ Tanko Ishaya, ${ }^{13}$ Godwin O Ovenseri-Ogbomo, (iD) ${ }^{1,14}$ Kingsley E Agho ${ }^{1,15}$

'African Vision Research Institute (AVRI), School of Health Sciences, University of Kwazulu-Natal, Durban, 3629, South Africa; ${ }^{2}$ Translational Health Research Institute (THRI), Western Sydney University, Campbelltown, New South Wales, Australia; ${ }^{3}$ Department of Optometry and Vision Sciences, Queensland University of Technology, Brisbane, Queensland, Australia; ${ }^{4}$ Department of Public Health, Faculty of Allied Medical Sciences, College of Medical Sciences, University of Calabar, Calabar, Cross River State, Nigeria;

${ }^{5}$ School of Allied Health Sciences, Department of Optometry and Vision Science, University of Cape Coast, Cape Coast, Ghana; ${ }^{6}$ Department of Psychiatry, College of Health Sciences, University of Jos, Jos, Nigeria; ${ }^{7}$ Health division, University of Bamenda, Bamenda, Cameroon; ${ }^{8}$ County Durham and Darlington National Health Service (NHS) Foundation, Darlington, Durham, UK;

${ }^{9}$ Department of Optometry and Vision Sciences, School of Public Health, Biomedical Sciences and Technology, Masinde Muliro University of Science and Technology, Kakamega, Kenya; ${ }^{10}$ Tanzania Food and Nutrition Center, Dar-es Salaam, Tanzania; "'Supply Chain Management, Curtin Business School, School of Management and Marketing, Curtin University, Perth, Western Australia, Australia; ${ }^{12}$ Department of Community Medicine, College of Health Sciences, University of Jos, Jos, Plateau State, Nigeria; ${ }^{13}$ Department of Computer Science, University of Jos, Jos, Plateau State, Nigeria; ${ }^{14}$ Department of Optometry, Centre for Life Sciences, University of the Highlands and Islands, Inverness, IV2 3JH, UK; ${ }^{15}$ School of Health Sciences, Western Sydney University, Sydney, New South Wales, Australia

Correspondence: Uchechukwu Levi Osuagwu Translational Health Research Institute (THRI), School of Medicine, Western Sydney University, Campbelltown, NSW, 2560, Australia

Tel +6I 40I 193234

Email l.osuagwu@westernsydney.edu.au
Purpose: The key preventive measures adopted to minimise the spread of the coronavirus disease (COVID-19) had significant health, economic and physical impacts mostly in developing countries. This study evaluated the health, economic and physical impacts of COVID19 lockdown measures among sub-Saharan African (SSA) population and associated demographic variations.

Methods: A total of 1970 respondents took part in this web-based cross-sectional survey during the mandatory lockdown period in most SSA. The dependent variables were health (COVID-19 infection, hospitalisation), socioeconomic (lost job, closed down business) and physical impacts (separated from family) of COVID-19. Univariate and bivariate logistic regression analyses were used to explore the factors associated with each of the dependent variables by the four sub-regions (Southern, Western, Central and East Africa).

Results: The respondents were aged $34.1 \pm 11.5$ years (range: $18-75$ years) and mostly men (1099, 55\%). $25.9 \%(n=511)$ reported an impact of COVID-19 pandemic with significant regional variations $(\mathrm{p}<0.0005$, higher proportion were East $36.2 \%$ and Southern Africans $30.3 \%)$ but no gender $(\mathrm{p}=0.334)$ and age group variations $(\mathrm{p}>0.05)$. Among Central African respondents, more men than women lost their businesses $(45.7 \%$ versus $14.3 \%, \mathrm{p}=$ $0.002)$ and contracted COVID-19 infections (40.0\% versus $18.2 \%, p=0.024)$ during the study period. Multivariable analysis revealed that respondents from East (adjusted odds ratio [AOR] 1.95, 95\% confidence interval [CI]: 1.42-2.69), Southern (AOR 1.46, 95\% CI: 1.09 1.96) and Central Africa (AOR 1.47, 95\% CI: 1.06-2.03) reported significantly higher impact of COVID-19. Those who reported family separation during the lockdown were more likely to be older participants (39-48 years, AOR 2.48, 95\% CI: $1.11-5.57$ ).

Conclusion: One in four SSA respondents, mostly East and Southern Africans, were adversely affected by the COVID-19 pandemic during the lockdown. Interventions in highrisk populations are needed to reduce the health, socioeconomic and gender disparities in the impacts of COVID-19.

Keywords: job loss, infections, hospitalisation, family separation, lockdown, coronavirus infection, Africa

\section{Introduction}

The coronavirus disease (COVID-19) pandemic has had significant health and economic impacts largely as a consequence of the key preventive measures adopted by most countries to minimise the spread of the virus. ${ }^{1,2}$ These measures include partial or complete lockdowns of economies resulting in temporary closures of airports, businesses, schools and social services. The pandemic was a profound 
shock to societies and economies, and underscores society's reliance on women both on the front line and at home. ${ }^{3}$ The pandemic simultaneously exposed structural inequalities in health, economy, security and social protection, and intensified gender inequality in Africa with many women having to work harder than before while earning even less than they normally would. ${ }^{4,5}$ In China, women make up more than $90 \%$ of health-care workers in Hubei province $^{6}$ and in Africa, about $70 \%$ of nurses are women; ${ }^{7}$ highlighting the gendered nature of the health workforce and the increased risk that female health workers are exposed to. ${ }^{8}$ No policies and public health efforts have yet addressed the gendered impacts of disease outbreaks globally, ${ }^{9}$ and this lack of action continues even in the response to coronavirus disease (COVID-19), worse still among SSA countries.

As noted in India, where a majority of residents in rural areas depend on foreign remittances, in the month immediately after the lockdown announcement, weekly household local income dropped by $88 \%$ compared to the long-term average with another $63 \%$ reduction in foreign remittances. ${ }^{10}$ The loss of jobs and income and the inability to access hospital services during the lockdown were also linked to psychosocial distress among respondents in India. ${ }^{11}$ In a South African study on the economic impacts of the pandemic in the hotel industry, ${ }^{12}$ researchers reported that $99.7 \%$ of the hotels were negatively impacted by the COVID-19 pandemic. This included $67 \%$ that reported a decline in income, $30.2 \%$ stated they expected that $90-100 \%$ of their staff would lose their jobs during the lockdown and many of the hotels were at risk of bankruptcy $(62.8 \%)$ and permanent business closure. ${ }^{12}$ These studies highlighted the need for micro survey data showing the economic impacts of COVID-19 lockdowns on poor and vulnerable households living in other developing countries. ${ }^{10}$ However, no study has examined the differential effects of COVID-19 impact by the different sub-regions.

SSA countries face many health and economic challenges, and the impact of COVID-19 in this region could be higher than that in developed economies. ${ }^{13,14}$ Although SSA countries were the last to register COVID-19 cases, ${ }^{15}$ the region has been reporting high infection rates while other regions, ${ }^{16}$ which have trade links with SSA such as China, have started to flatten out with economic stimulus and investment plans underway. In addition, while the rest of the world is emerging from the global slowdown and reopening businesses, ${ }^{17,18}$ the trend in SSA economies seems to veer towards a deeper recession with further possibilities of production and trade-related constraints if infection rate continues to rise. ${ }^{19}$

In addition, demographic, political, cultural and health issues in the sub-regions of SSA are different, which implies that the impact of COVID-19 may be different. ${ }^{19}$ For example, over nine percent of Mauritius' population was 60 years and older in 2005, making it the oldest country in SSA while other Southern African countries such as South Africa and Lesotho had approximately eight percent of their populations aged 60 and older. Countries such as Benin, Burundi, Kenya, Mauritania, Rwanda, Uganda, and Zambia had older populations accounting for less than four percent of the total population. ${ }^{20}$ In terms of HIV infections, Southern African countries of Botswana and Swaziland have the highest rates, while West Africa has been relatively less affected by HIV infection compared to other regions of SSA. ${ }^{21}$ Furthermore, data from the World Health Organisation has shown that strata with lower socioeconomic status are more prone to the dangers of COVID-19. ${ }^{22}$

The poor economic resilience and differences in sociodemographic variables among different sub-regions of SSA exposes the region to greater risks of serious negative impacts from the COVID-19 pandemic. For instance, in Ethiopia where there were no direct restrictions imposed on the agriculture sector (the primary means of livelihood for most people) during the pandemic, researchers projected that the sector could face a $4.7 \%$ loss in output due to its linkages with the rest of the economy. ${ }^{23}$ Therefore, this study was carried out to investigate the health, economic and physical impacts of COVID-19 and their associations with variables such as gender, age and region of origin, among respondents living in SSA countries. Recognising these impacts and their associations with gender and regional variations is an important step to understanding the primary and secondary effects of a health emergency on different individuals and communities, and for creating effective, equitable policies and interventions. $^{24}$

\section{Materials and Methods Study Population}

Respondents were from sub-Saharan African countries including those living abroad and in their countries of origins from Ghana, Cameroun (only distributed to the English-speaking regions), Nigeria, South Africa, 
Tanzania, Kenya, Uganda, etc. Respondents who were 18 years and older, and able to provide online consent were considered for the survey.

\section{Study Design}

A cross-sectional descriptive study was conducted over a period of one month (April 18 to May 18, 2020) corresponding to the period of mandatory lockdown and restriction of movement in most of the countries surveyed. The data were obtained electronically via survey monkey with an e-link of the structured synchronised questionnaire posted on Facebook and WhatsApp which were commonly used by the locals in the participating countries and was sent via emails by the researchers to facilitate responses. Online survey was the only feasible way of reaching people as we could not perform nationwide communitybased sample survey during this period.

\section{Survey Questionnaire}

The questionnaire included a brief overview of the context, purpose, procedures, nature of participation, privacy and confidentiality statements and notes to be filled out. The items were developed based on COVID-19 knowledge questionnaire guidelines of the World Health Organization (WHO) for clinical and community management of COVID-19. A sample of the questionnaire has been reported previously ${ }^{25}$ including the details of initial pilot. However, for the purpose of this study, the section utilised in the analysis is shown in Supplementary Table.

\section{Outcome Variables}

The main outcome variable was any impact of COVID-19, which was coded as ' 1 ', if the participants reported that they or any family member was affected by COVID-19 and ' 0 ' if they reported no impact of COVID-19. The secondary outcomes were five items on the impact of COVID-19 including whether or not the participant or a family member a) lost their job, b) closed down business, c) contracted COVID-19, d) hospitalised due to COVID19 , and e) were completely separated from their families during the lockdown period.

\section{Independent Variables}

The independent variables included the demographic characteristics of the participants: age (divided into four age groups including 18-28, 29-38, 29-48 and 49+ years based on the distribution), region of origin (West, East, Southern and Central Africa), religion (Christian and others), educational (Postgraduate including masters and $\mathrm{PhD}$, undergraduate University degree, primary/secondary school), marital (married/de facto and others including widowed, divorced, separated, and single), employment and occupational status (working in healthcare and nonhealthcare sectors).

\section{Data Analysis}

Demographic and the outcome variables were summarised as counts and percentages for categorical variables and two-way frequency table was used to obtain the proportion estimates for each sub-region. The level of association between gender and the impact of COVID-19 was tested using Fisher's exact test by sub-region. Having any impact of COVID-19 was considered as 'yes' if participants reported any of the following outcomes: lost job, closed business, contracted COVID-19, hospitalised and separated from family, and "no" if they did not report any of the five impacts.

In the univariate and bivariate analyses, odds ratios with 95\% confidence intervals were calculated in order to assess the unadjusted risk of independent variables on the dependent variables. Following the univariate logistic regression analysis, variables with a $P$-value $<0.20$ were retained and used to build a multivariable logistic regression model which examined the factors associated with the impacts of COVID-19 pandemic. We conducted bivariate logistic regressions to determine factors associated with 'any impact of COVID-19', and for each of the five impacts of COVID-19 during the pandemic at $P<0.05$. Significant factors in the univariate analysis were added to the regression model. The odds ratios with 95\% confidence intervals were also calculated to assess the adjusted factors. All statistical analyses were performed using the Statistical Package for Social Sciences (SPSS, version 26, IBM, Armonk, NY, USA).

\section{Ethical Considerations}

Ethical approval for the study was sought and obtained from the Human Research Ethics Committee of the Cross River State Ministry of Health (CRSMOH/HRP/HREC/ 2020/117). The study was carried out in accordance with the Helsinki Declaration for Human Research. The confidentiality of participants was assured in that no identifying information was obtained from participants. Participants were required to answer a "yes" or "no" to the consent question during survey completion to indicate their willingness to participate in this study. 


\section{Results}

Of the 2032 completed surveys, data for 1970 (96.9\%) participants from West Africa (56.1\%), Southern Africa (20.4\%), Central Africa (12.7\%) and East Africa (10.8\%) who responded to the items on the impact of COVID-19 were analysed. The respondents were aged $34.1 \pm 11.5$ years (mean \pm standard deviation; range: $18-75$ years) and mostly men (1099, 55\%). Other demographic details showing the participants' characteristics by sub-regions are provided in Table 1.
Respondents from West Africa were significantly older (17.7\% aged 49 years and above) and those from Central Africa were significantly younger $(\mathrm{p}<0.04$, $54.6 \%$ aged $18-28$ years) than those from other regions (Table 1). A total of $510(25.9 \%)$ respondents reported an impact of COVID-19 during the pandemic including economic (300 [45.0\%] lost their jobs and 177 [27.5\%] lost their businesses), health (143 [22.1\%] contracted the virus and 255 [38.3\%] were hospitalised due to COVID$19)$ and physical impacts (178 [27.4\%] were completely

Table I Demographic Characteristics of the Respondents $(N=1970)$ by Sub-Saharan African Sub Region. Values are Number (Percentages) Except for Age

\begin{tabular}{|c|c|c|c|c|c|}
\hline Characteristics & $\begin{array}{l}\text { West Africa } \\
(n=\mid 105)\end{array}$ & $\begin{array}{l}\text { East Africa } \\
(n=2 \mid 3)\end{array}$ & $\begin{array}{l}\text { Southern Africa } \\
(n=402)\end{array}$ & $\begin{array}{l}\text { Central Africa } \\
(n=250)\end{array}$ & P-value \\
\hline \multicolumn{6}{|l|}{ Demographic variables } \\
\hline Age, mean $( \pm S D)$ & $35.6(11.1)$ & $33.8(8.0)$ & $34.1(14.0)$ & $28.2(9.2)$ & $<0.001 *$ \\
\hline \multicolumn{6}{|l|}{ Gender } \\
\hline Men & $684(62.2 \%)$ & 122 (36.5\%) & I55 (38.6\%) & 124 (49.8.4\%) & $<0.001$ \\
\hline Women & $415(37.8 \%)$ & $90(63.5 \%)$ & 247 (61.4\%) & $123(50.2 \%)$ & \\
\hline \multicolumn{6}{|l|}{ Employment status } \\
\hline Employed & 995 (90.4\%) & I82 (86.3\%) & 364 (90.5\%) & 199 (80.6\%) & $<0.001$ \\
\hline Unemployed & $106(9.6 \%)$ & 29 (I3.7\%) & $38(9.5 \%)$ & 48 (19.4\%) & \\
\hline \multicolumn{6}{|l|}{ Marital status } \\
\hline Single & 520 (47.2\%) & 90 (42.9\%) & 241 (60.0\%) & 178 (72.1\%) & $<0.001$ \\
\hline Married & 543 (49.3\%) & 119 (56.7\%) & I 38 (34.4\%) & $66(26.7 \%)$ & \\
\hline Other & $38(3.5 \%)$ & I $(0.4 \%)$ & $23(5.6 \%)$ & $3(1.2 \%)$ & \\
\hline \multicolumn{6}{|l|}{ Religion } \\
\hline Christian & $103 \mid(93.7 \%)$ & $19 \mid$ (90.5\%) & 286 (7I.1\%) & $230(93.5 \%)$ & $<0.001$ \\
\hline Other & $69(6.3 \%)$ & $20(9.5 \%)$ & $116(28.9 \%)$ & $16(6.5 \%)$ & \\
\hline \multicolumn{6}{|l|}{ Level of education } \\
\hline Postgraduate degree & 417 (37.9\%) & 82 (38.9\%) & 93 (23.2\%) & $4 \mathrm{I}(16.6 \%)$ & $<0.001$ \\
\hline University degree & $622(56.5 \%)$ & $120(56.9 \%)$ & $179(44.6 \%)$ & $149(60.3 \%)$ & \\
\hline High/Secondary/Primary school & $62(5.6 \%)$ & $9(4.2 \%)$ & $129(32.2 \%)$ & $57(23.1)$ & \\
\hline \multicolumn{6}{|l|}{ Occupation } \\
\hline Healthcare & $270(24.5 \%)$ & $55(26.1 \%)$ & $72(17.9 \%)$ & $39(15.8 \%)$ & 0.001 \\
\hline Non-Healthcare & 831 (75.5\%) & I56 (73.9\%) & $330(82.1 \%)$ & $208(84.2 \%)$ & \\
\hline \multicolumn{6}{|l|}{ Main Outcome variables } \\
\hline \multicolumn{6}{|l|}{ Impact of COVID-19 } \\
\hline Lost job & 152 (45.9\%) & $47(56.0 \%)$ & 61 (37.9\%) & $41(45.1 \%)$ & 0.058 \\
\hline Closed down business & $86(26.7 \%)$ & 26 (31.3\%) & $38(25.0 \%)$ & 27 (30.7\%) & 0.654 \\
\hline Contracted COVID-19 & 77 (23.6\%) & $24(29.6 \%)$ & $16(10.5 \%)$ & $26(29.2 \%)$ & $<0.001$ \\
\hline Hospitalized due to COVID-19 & $121(36.1 \%)$ & 32 (39.0\%) & $64(40.8 \%)$ & 38 (4I.3\%) & 0.682 \\
\hline Separated from family & $80(24.7 \%)$ & 27 (32.1\%) & $40(25.6 \%)$ & 31 (35.2\%) & 0.162 \\
\hline Any effect & $242(21.9 \%)$ & 77 (36.2\%) & $122(30.3 \%)$ & $70(28.0 \%)$ & 0.034 \\
\hline
\end{tabular}

Notes: $P$-values are results of comparison between regions, *results of univariate analysis of variance (ANOVA) for age, others are Chi Square association between regions and demographic characteristics. $P<0.05$ are statistically significant.

Abbreviations: COVID-19, novel coronavirus; SD, standard deviation. 
separated from their families) because of the pandemic. There was no significant effect of age group on any impact of COVID-19 across the regions $(p=0.112)$, although the effect of age approached significance $(\mathrm{p}=$ 0.071) among East Africans being slightly higher among 25-33 and 25-33 years age groups compared with the other age groups (Figure 1).

\section{Impact of COVID-19 According to Gender in the Four SSA Regions}

Using Chi-Square analysis, there was no statistically significant association between gender and any impact of COVID$19(p=0.334)$ in the pooled analysis. Figure 2 shows the percentage breakdown of participants who reported any of the five impacts of COVID-19 for the four SSA sub-regions. Significant gender effects were found only among Central African respondents where more men than women suffered from business closure $(45.7 \%$ versus $14.3 \%, \mathrm{p}=0.002)$ and contracted COVID-19 infections $(40.0 \%$ versus $18.2 \%$, $\mathrm{p}=$ 0.024). Proportionally, women were more impacted by COVID-19 than men in Southern Africa, but this association did not reach statistical significance.

\section{Impact of COVID-19 According to Region}

Figure 3 shows the percentage breakdown of respondents who experienced any impact of COVID-19 in each sub-region during the pandemic. There were statistically significant differences in the proportion of respondents who reported any impact of COVID-19 compared with those who did not report any impact of the pandemic within the sub-regions $(\mathrm{p}<$ $0.001)$. East (36.2\%) and Southern African (30.3\%) respondents were more likely to report any impact of the pandemic compared with those from the other sub-regions.

\section{Multivariable Analysis of Factors} Associated with the Impact of COVID-19 in the Four SSA Regions

After adjusting for the effects of gender, employment status, marital status, religion, level of education and occupation, which were significant in the previous analysis (see Table 1), multivariate logistic regression analyses revealed that the region of residence was the only factor associated with any impact of COVID-19 among the respondents. Those from East (Adjusted odds ratio [AOR] 1.95, 95\% confidence interval [CI]: 1.42-2.69), Southern (AOR 1.46, 95\% CI: 1.09-1.96) and Central Africa (AOR 1.47, 95\% CI: 1.06-2.03) had higher odds of any impact of COVID-19 than West Africans.

Similar regression analysis conducted with each of the five impacts of COVID-19 (Figure 2) as a dependent variable showed that age was significantly associated with closure of business. Respondents aged 18-28 years (AOR 0.28, 95\% CI: $0.11-0.72$ ), $29-38$ years (AOR $0.43,95 \%$ CI: $0.19-0.99$ ),

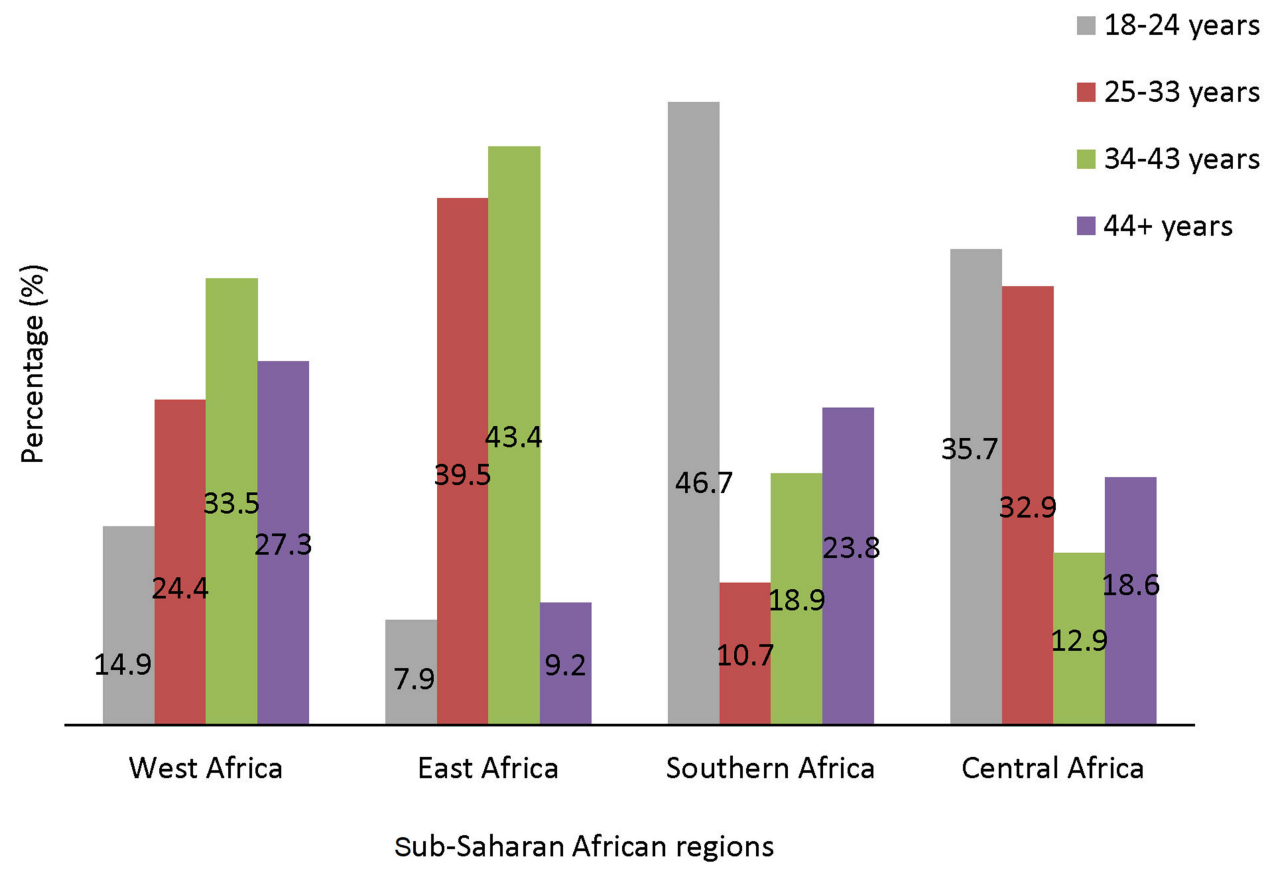

Figure I Percentage distribution of any impact of COVID-19 during the lockdown in the sub-Saharan African regions by age group $(\mathrm{n}=1970)$. 

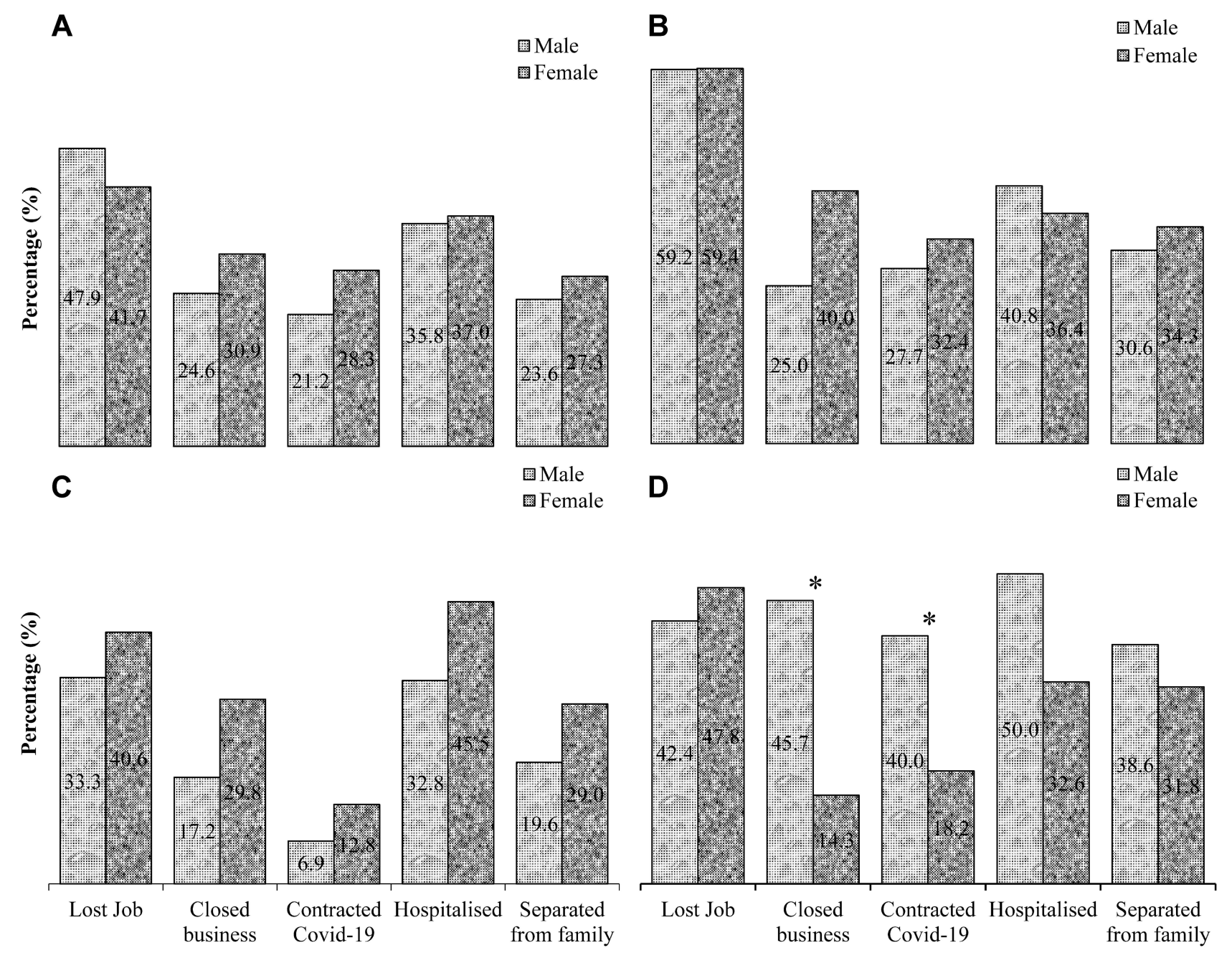

Figure 2 Percentage breakdown of the impacts of COVID-19 (lost jobs, closed down businesses, contracted COVID-I9, hospitalized due to COVID-I9 and physical separation from families) during the lockdown in the sub-Saharan African regions by gender: West Africa (A), East Africa (B), Southern Africa (C) and Central African (D) regions $(n=1970)$. *Indicates a significant difference in the impact of COVID-19 between men and women $(p<0.05$, independent $t$-test).

39-48 years (AOR 0.53, 95\% CI: 0.29-0.99) had lower odds of closing their business than those aged $49+$ years. Similarly, those aged 39-48 years had higher likelihood of separating from family during the lockdown (AOR 2.48, 95\% CI: $1.11-$ 5.57). Compared with West African respondents, Southern Africans reported a lower likelihood for contracting COVID19 (AOR 0.21, 95\% CI: 0.10-0.47) during the lockdown, while those who were employed were marginally less likely to contract COVID-19 (AOR 0.53 95\% CI: 0.25-1.01) compared to those who were unemployed at the time of this study.

\section{Discussion}

The COVID-19 cases started in late 2019 in China and spread sporadically across the world presenting one of the most serious global health crises. While its impact on the world's economic and health systems including morbidities and mortalities continue to rise, the full extent of its toll in different SSA regions has not been investigated. We investigated the health, economic and physical impacts of COVID-19 and their associated demographic variations. The results showed that there were gender and regional variations on the impact of COVID-19 and these were in line with recent predictions. ${ }^{19}$ East and Southern African respondents reported the highest impacts of COVID-19 (about one-third of the respondents) followed by Central and the least impact was found among West African respondents. After adjusting for all potential confounders, we found that East and Southern African respondents were more likely to report any impact of COVID-19 compared to West African respondents. During the lockdown, Southern African respondents reported lower likelihood of contracting COVID-19 compared with West 


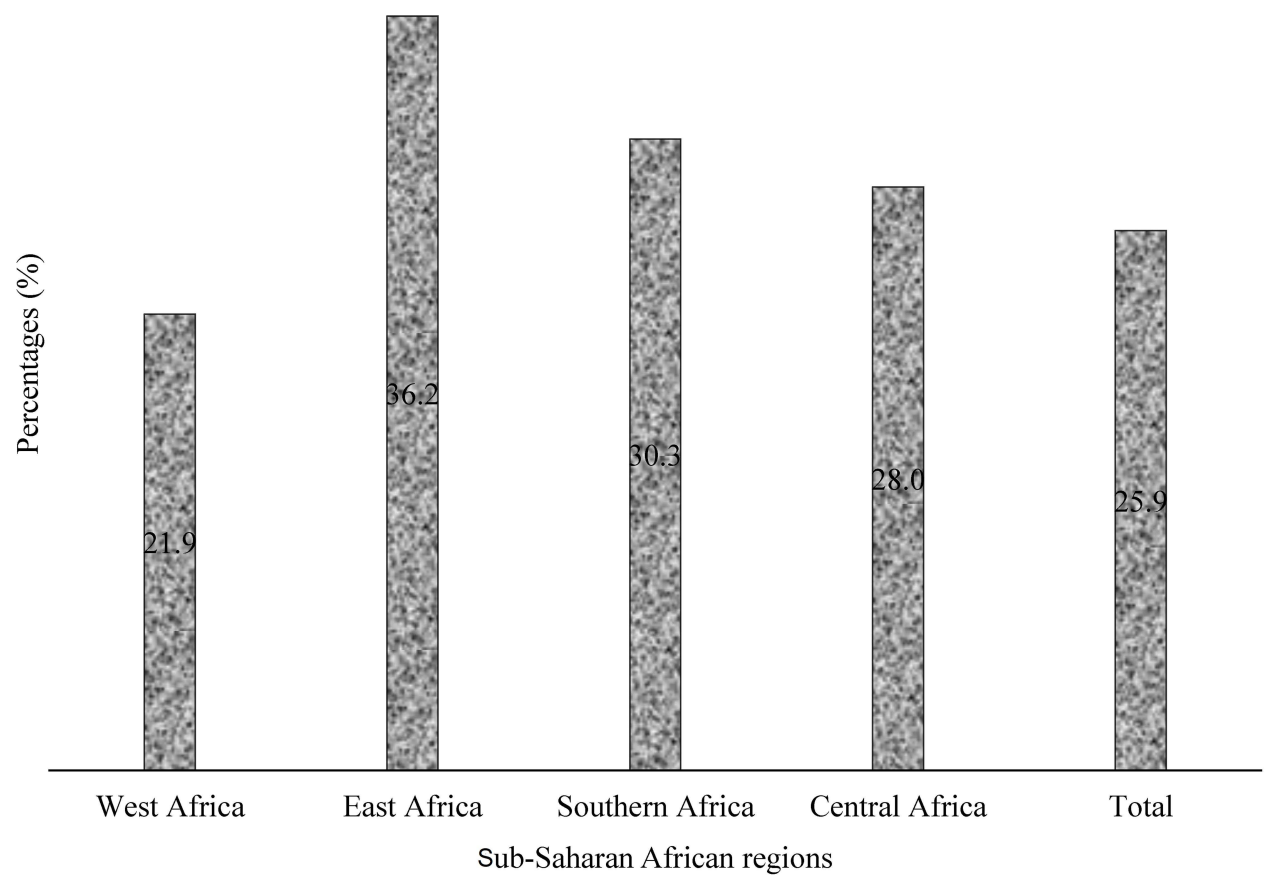

Figure 3 Percentage distribution of any impact of COVID-19 by sub-Saharan African sub-region $(n=1970)$.

Africans in this study. Overall, more people in SSA reported shutting their businesses during the pandemic, and the effects were mostly felt among persons older than 49 years.

In this study, the effect of gender was depended on the variable used to measure the impact of COVID-19 and this varied between the sub-regions in SSA. For instance, in Central Africa, men were disproportionately impacted by COVID-19 and suffered greater business shut downs and contracting COVID-19 disease than the women. This could be a reflection of gender inequalities in most Central African countries. During humanitarian crises, such as pandemics, men and women are affected differently. ${ }^{7}$ However, in Southern Africa, there was a tendency for greater impact of COVID-19 among women than men. ${ }^{7}$ In addition, as the disease spreads in this sub region, there are also concerns over its impact on women and girls, whose vulnerabilities may worsen as it overwhelms the already poor health systems. ${ }^{7}$ The impact of COVID-19 in West and Eastern Africans between males and females was the same, except for marginal differences in job losses among Western Africans and closure of businesses in both sub-regions. These results are different from what was generally observed during the Ebola outbreak, where gendered norms meant that women were more likely to be infected by the virus, given their predominant roles as caregivers within families and as front-line health-care workers. ${ }^{24}$ Unlike their male counterparts, women were less likely to have power in decision making around the outbreak, and their needs remained largely unmet. ${ }^{26}$ Further investigations are required to fully comprehend the contrasting regional variations on the influence of gender on the impact of COVID-19.

The finding of higher impact of COVID-19 among East and Southern African respondents could have been influenced by the nature of lockdowns adopted during the time of the study in the different sub regions of SSA. For example, most countries in the East and Southern African countries adopted complete lockdowns, which may have resulted in low economic productivity and disruptions to key value trading chains in those regions. ${ }^{27}$ Individuals in these countries were restricted to their homes except under strict controlled circumstances such as seeking of medical care, buying food, medicine and other essential supplies or the collection of social grants. On the other hand, in Western African countries such as Ghana and Nigeria and many Central African countries, there was a partial lockdown and many businesses including small, medium and informal businesses that sustain the livelihoods of the majority of citizens, were still in operation during the time of this study. The informal sector carries a significant weight in most Sub Saharan African 
economies. $^{28}$ The reported lower likelihood of Southern Africans to contract COVID-19 during the lockdown compared with West Africans could be due to the relatively young mean age of the Southern African respondents in this study (34.1 \pm 14 years) who had a high proportion of their population between 18 and 24 years (Figure 1).

The study found that persons aged 49 years and older were more likely to shut down their businesses during lockdown compared with those younger than 48 years. As reported, COVID-19 can lead to hospitalisation and death for young adults; however, it causes the most severe health issues in adults. ${ }^{29}$ It has been shown that older adults (over 65 years of age) represent $80 \%$ of hospitalisations and have a 23 -fold greater risk of death than younger adults (under 65 years). ${ }^{29}$ Although it is not known why SARS-CoV-2 infections are more severe and fatal in the aged, ${ }^{29}$ knowledge of this may have resulted in adult respondents taking the necessary precautions of shutting their businesses and staying at home to curtail their risk of contracting the virus. This assertion is further supported by the fact that those aged 39-48 years were more likely to be separated from their families during the lockdown compared with older respondents $49+$ years in this study.

This study has some limitations. The cross-sectional design of this study made it impossible to determine causation. Given the inability to physically access respondents due to the pandemic, the survey tool was sent out to prospective respondents electronically using social media platforms and emails. This method of soliciting respondents may have inadvertently excluded some potential participants whose opinion may have differed, such as those without internet access, and people living in rural areas where internet penetration remains relatively low. ${ }^{30}$ However, the use of an internet-based methodology was the only reliable means to disseminate information at the time of this study. Furthermore, the survey was presented in the English language and those from non-English speaking countries in SSA may not have participated. Notwithstanding these limitations, this was the first study from the SSA region to provide regional insight into some of the socioeconomic and health impact of the pandemic suffered by residents during the lockdown period. Although this subject is commonplace as it is expected to happen during pandemics, no study has demonstrated these impacts of COVID-19 in the way the present study did, particularly at a regional level among Africans. This makes our study a unique one, since it provided the first documented regional evidence showing the impacts of the lockdown on the ordinary citizen. The study was presented at the $9^{\text {th }}$ Scientific Conference of the Epidemiological Society of Nigeria an affiliate of the International Epidemiological Association at which public health experts stated that the paper provided evidence for impacts that had hitherto been anecdotal. The use of a robust analysis to control for potential confounders during the analysis reduced the possibility of a bias.

\section{Conclusion}

This study showed that gender had an influence on the impact of COVID-19 in the Central African sub-region. The pandemic was reported to have a more significant impact on East and Southern Africans compared with West African respondents, possibly due to the differences in the nature of the lockdowns in these sub-regions. In addition, older adults ( $>49$ years) were more likely to shut down their businesses during the pandemic. The findings of this study suggest that COVID-19 has an effect on health, economic and social fabric of society in this region. As the pandemic intensifies and communities suffer significant disruptions, ongoing efforts need to be intensified to prevent increased morbidity and mortality. SSA countries need to learn from each other during this recovery period, and policy instruments that include holistic approach should be implemented, to reduce human suffering and enhance the recovery of the economy in the different sub-regions. There is need for further studies examining other indices of economic and health impacts of the COVID-19 outbreak in the SSA regions.

\section{Disclosure}

The authors report no conflicts of interest in this work.

\section{References}

1. IWDA. COVID-19 Impacts Women Differently, and Here's How. International Women's Development Agency; 2020.

2. Nicola M, Alsafi Z, Sohrabi C, et al. The socio-economic implications of the coronavirus and COVID-19 pandemic: a review. Int $j$ Surg. 2020;78:185-193. doi:10.1016/j.ijsu.2020.04.018

3. UN. Explainer: How COVID-19 Impacts Women and Girls. UN Women. New York, NY: United Nations; 2020.

4. Power K. The COVID-19 pandemic has increased the care burden of women and families. Sustainability. 2020;16:67-73.

5. McLaren HJ, Wong KR, Nguyen KN, Mahamadachchi KND. Covid19 and Women's Triple Burden: vignettes from Sri Lanka, Malaysia, Vietnam and Australia. Soc Sci. 2020;9:87. doi:10.3390/socsci9050087

6. Chen N, Zhou M, Dong X, et al. Epidemiological and clinical characteristics of 99 cases of 2019 novel coronavirus pneumonia in Wuhan, China: a descriptive study. The Lancet. 2020;395:507-513. doi:10.1016/S0140-6736(20)30211-7 
7. UNECA. Africa's Responses to COVID-19 Must Be Gender Responsive. Africa Renewal; May 14, 2020.

8. Boniol M, McIsaac M, Xu L, Wuliji T, Diallo K, Campbell J. Gender Equity in the Health Workforce: Analysis of 104 Countries. World Health Organization; 2019.

9. Smith J. Overcoming the 'tyranny of the urgent': integrating gender into disease outbreak preparedness and response. Gend Dev. 2019;27:355-369. doi:10.1080/13552074.2019.1615288

10. Gupta A, Zhu H, Doan MK, Michuda A, Majumder B. Economic impacts of the COVID- 19 lockdown in a remittance-dependent region. Am J Agric Econ. 2021;103:466-485. doi:10.1111/ajae.12178

11. Singh K, Kondal D, Mohan S, et al. Health, psychosocial, and economic impacts of the COVID-19 pandemic on people with chronic conditions in India: a mixed methods study. BMC Public Health. 2021;21:685. doi:10.1186/s12889-021-10708-w

12. Sucheran R. Preliminary economic impacts of the COVID-19 pandemic on the hotel sector in South Africa. Afr J Hosp Tourism Leisure. 2021;10:115-130. doi:10.46222/ajhtl.19770720-90

13. Ozili P. COVID-19 in Africa: socio-economic impact, policy response and opportunities. Int J Sociol Soc Pol. 2020. doi:10.1108/ IJSSP-05-2020-0171

14. Erokhin V, Gao T. Impacts of COVID-19 on trade and economic aspects of food security: evidence from 45 developing countries Int J Environ Res Public Health. 2020;17:5775. doi:10.3390/ ijerph17165775

15. Lalaoui R, Bakour S, Raoult D, et al. What could explain the late emergence of COVID-19 in Africa? New Microbes New Infect. 2020;22:100760.

16. Mwai P. Coronavirus: Africa's new variants are causing growing concern. BBC News. February 13, 2021.

17. Fakhruddin BS, Blanchard K, Ragupathy D. Are we there yet? The transition from response to recovery for the COVID-19 pandemic. Prog Disaster Sci. 2020;7:100102. doi:10.1016/j.pdisas.2020.100102

18. Fairlie R. The impact of COVID-19 on small business owners: evidence from the first three months after widespread social-distancing restrictions. J Econ Manage Strategy. 2020;29:727-740. doi: $10.1111 /$ jems. 12400
19. Gilbert M, Pullano G, Pinotti F, Valdano E, Poletto C, et al. Preparedness and vulnerability of African countries against importations of COVID-19: a modelling study. The Lancet. 2020;39 5:871-877. doi:10.1016/S0140-6736(20)30411-6

20. Council NR. Aging in Sub-Saharan Africa: Recommendations for Furthering Research. In: Cohen B, Menken J, editors. Washington DC: The National Academies Press; 2006.

21. Dwyer-Lindgren L, Cork MA, Sligar A, et al. Mapping HIV prevalence in sub-Saharan Africa between 2000 and 2017. Nature. 2019;570:189-193. doi:10.1038/s41586-019-1200-9

22. Organization WH. Coronavirus Disease 2019 (COVID-19): Situation Report. Vol. 86; 2020.

23. Aragie E, Taffesse AS, Thurlow J. The short-term economywide impacts of COVID-19 in Africa: insights from Ethiopia. Afr Develop Rev. 2021;33:S152-S164. doi:10.1111/1467-8268.12519

24. Davies SE, Bennett B. A gendered human rights analysis of Ebola and Zika: locating gender in global health emergencies. Int Aff. 2016;92:1041-1060. doi:10.1111/1468-2346.12704

25. Ovenseri-Ogbomo G, Ishaya T, Osuagwu UL, et al. Factors associated with the myth about $5 \mathrm{G}$ network during COVID-19 pandemic in sub-Saharan Africa. J Global Health Rep. 2020;4:e2020094.

26. Harman S. Ebola, gender and conspicuously invisible women in global health governance. Third World Q. 2016;37:524-541. doi:10.1080/01436597.2015.1108827

27. Arndt C, Davies R, Gabriel S, et al. Covid-19 lockdowns, income distribution, and food security: an analysis for South Africa. Global Food Security. 2020;26:100410. doi:10.1016/j.gfs.2020.100410

28. Gondwe G, editor Assessing the impact of COVID-19 on Africa's economic development. United Nations Conference on Trade and Development; 2020.

29. Mueller AL, McNamara MS, Sinclair DA. Why does COVID-19 disproportionately affect older people? Aging (Albany NY). 2020;12:9959. doi:10.18632/aging.103344

30. Hjort J, Poulsen J. The arrival of fast internet and employment in Africa. Am Econ Rev. 2019;109:1032-1079. doi:10.1257/aer.20161 385
Risk Management and Healthcare Policy

\section{Publish your work in this journal}

Risk Management and Healthcare Policy is an international, peerreviewed, open access journal focusing on all aspects of public health, policy, and preventative measures to promote good health and improve morbidity and mortality in the population. The journal welcomes submitted papers covering original research, basic science, clinical \& epidemiological studies, reviews and evaluations, guidelines, expert opinion and commentary, case reports and extended reports. The manuscript management system is completely online and includes a very quick and fair peer-review system, which is all easy to use. Visit http://www.dovepress.com/testimonials.php to read real quotes from published authors. 